\title{
Malingering mental disorders: clinical assessment ${ }^{\dagger}$
}

\author{
Derek K. Tracy \& Keith J. B. Rix
}

\begin{abstract}
SUMMARY
Malingering is the dishonest and intentional production of symptoms. It can cause considerable difficulty as assessment runs counter to normal practice, and it may expose clinicians to testing medicolegal situations. In this first part of a twoarticle review, we explore types of psychiatric malingering and their occurrence across a range of common and challenging scenarios, discussing presentations that may help delineate true from feigned illness. A framework is provided for undertaking an assessment where malingering is suspected, including recommendations on clinician approach, the use of collateral information, and self-evaluation of biases. The uses, and limitations, of psychometric tests are discussed, including 'general', malingering-specific and 'symptom validity' scales.
\end{abstract}

\section{LEARNING OBJECTIVES}

- Understand the challenges of determining 'real' from 'malingered' symptomatology across a range of psychiatric conditions

- Have a rational strategy for approaching a clinical assessment where malingering is suspected

- Appreciate the role and limitations of various psychometric tests that can be used in such assessments

\section{DECLARATION OF INTEREST}

None

'The study of malingering has, we fear, been somewhat neglected by the scientific Physician, who, bent on establishing the features of true disease, has instinctively recoiled from the study of feigned disorders' - A. Bassett Jones \& L. J. Llewellyn, Malingering, or, The Simulation of Disease, 1918.

Malingering is the dishonest and intentional production or exaggeration of physical or psychological symptoms for external gain. It differs from factitious disorders, such as Munchausen syndrome, in which the gain is psycho(patho) logical secondary benefit, although debate exists on how professionals may ascribe one diagnosis over another on the basis - perhaps subconsciously or unintentionally - of individuals' social backgrounds (Kanaan 2010). In art and history, such feigning has been recorded over millennia: from
Odysseus sowing salt instead of seed to convince Agamemnon of his madness and avoid combat in the Trojan War, to the Roman physician Galen's description of an individual malingering colic to avoid a meeting (Lund 1941). In more recent times, 'post-traumatic neurosis', a diagnostic precursor of post-traumatic stress disorder (PTSD), was first proposed in 1882 in reaction to industrial railway accidents (Erichsen 1882), with simultaneous recognition that this could lead to false claims for compensation. Through both World Wars individuals - perhaps not unreasonably - feigned various illnesses to avoid military combat, and indeed Allied Forces dropped pamphlets on German troops encouraging this behaviour (Richards 2010).

Malingering is not a mental illness - so one suspects, possibly detects, but does not diagnose it - although psychiatrists and psychologists will encounter such behaviour both through requested explicit assessments and as an unexpected occurrence in clinical practice, and it is coded by both ICD-10 (World Health Organization 1992) and DSM-5 (American Psychiatric Association 2013). It poses particular challenges as it runs counter to and can confront usual clinical practice and relationship building, and may expose professionals to highly testing legal situations.

It is self-evidently difficult to ascertain reliable figures on rates of malingering: Mittenberg et al's influential survey (2002) of over 30000 clinical reports determined probable malingering in almost a third of personal injury and disability cases and $8 \%$ of medical cases. These data are reasonably consistent with a survey of medical experts (Allcott 2014), the majority of whom estimated that less than a quarter of reviewed cases were not genuine. However, it would appear reasonable to surmise that there may be considerable variation between different psychiatric 'illnesses', demographic groups and geographical locations.

A crucial concept is that malingering is not necessarily a binary 'present' or 'absent' phenomenon. Lipman identified (1962) four types:

- invention of symptoms

- perseveration, or describing symptoms that previously existed
ARTICLE

Derek Tracy is a consultant psychiatrist and the Associate Clinical Director for crisis, in-patient and rehabilitation services at Oxleas NHS Foundation Trust, London. He is a Biomedical Research Centre Research Fellow and runs MSc modules in psychopharmacology and mental health in the community at the Institute of Psychiatry, Psychology and Neuroscience, King's College London. Keith Rix is honorary consultant forensic psychiatrist with Norfolk and Suffolk NHS Foundation Trust, and Visiting Professor of Medical Jurisprudence at the University of Chester, where he is involved with its MSc in Medicolegal Practice. $\mathrm{He}$ is an elected Honorary Fellow of the Faculty of Forensic and Legal Medicine of the Royal College of Physicians.

Correspondence Dr Derek K. Tracy, The Memorial Hospital, Shooter's Hill, London SE18 3RG. Email: derek.tracy@nhs.net

Copyright and usage (C) The Royal College of Psychiatrists 2017.

This is the first of two articles on psychiatric malingering. The second, which will appear in the March issue, will consider the challenges for the expert when presenting findings in the medicolegal context: Rix KJB, Tracy DK (2017) Malingering mental disorders: medicolegal reporting. BJPsych Advances, in press. 
- exaggeration of real symptoms

- transference, or attributing real symptoms to a false cause.

One of us has previously written on malingering detection specifically in memory and cognitive examinations (Tracy 2014): this is a somewhat easier process insofar as one can evaluate effort and look at probabilistic response patterns. Herein we aim to explore the far greater task of the detection of malingering across a range of psychiatric diagnoses. The unique challenge of psychiatry is that we lack reliable objective biomarkers and depend on the subjective recollection and description of psychological phenomena, alongside collateral data, the mental state examination and our expert knowledge and experience of mental disorder. Individuals may feign, exaggerate or misattribute symptoms, and falsely complete clinical scales.

\section{Malingering by diagnostic category}

\section{Post-traumatic stress disorder}

PTSD probably represents the great malingering challenge of our time. It has a definable (and diagnostically essential) clear cause, which can lead to compensation litigation and various other claims for assistance. As such, the potential for unscrupulous manipulation is obvious and, indeed, PTSD is the only condition for which DSM-5 specifically warns clinicians to watch for malingering. Jones \& Milroy (2016) note that 'the embellishment of a warrior biography has a long history but examples of veteran elaboration of traumatic experience have become increasingly apparent'. The former psychiatric lead for the UK veterans' mental health service medical assessment programme has gone on public record (Townsend 2016) expressing his expert opinion that in over $40 \%$ of cases mental health problems had no definite link to military service, and in $10 \%$ of cases veterans appeared to be making up or exaggerating their service history.

\section{Difficulties in assessing PTSD}

There are five serious difficulties for clinicians assessing PTSD. The first is that an individual might have suffered very real and genuine physical and psychological traumas, but be amplifying their degree or result. Such exaggeration is probably the most common form of PTSD malingering (Kleinman 2004), and of course an individual might have suffered a genuine trauma to a degree that would have precipitated PTSD in another, more vulnerable, individual, yet not develop the condition themselves.
The second is that, for many, the potential external gain is considerable, including, but not limited to, avoiding military duty, obtaining financial compensation, assisting an asylum claim or avoiding criminal responsibility.

Third, particularly in the case of those fleeing, there are considerable potential dangers of unexamined clinician countertransference positive or negative - when hearing traumatic histories, and the risk of the unintentional introduction of bias.

Fourth, the validity of applying the same diagnostic criteria to very heterogeneous groups has been challenged: for example, there is debate about how generalisable research on civilian trauma exposure is to military groups and vice versa (Yehuda 2014), including further subgroup division, such as the notable differences in PTSD prevalence between UK and US service personnel (Hunt 2014). This issue is further compounded by the application of PTSD diagnostic criteria to different - especially non-Western - cultural groups (Slobodin 2015), with serious conceptual challenges in interpreting how culture, religion and gender might produce variation in presentation of symptoms of distress and mental illness.

Finally, with particular reference to refugee populations, one must be cognisant of:

- individuals' relationships with, and experience of, professionals, including previous (potentially traumatic) encounters with figures of authority and power

- linguistic challenges if English is not a first language and/or an interpreter is used.

\section{Distinguishing real from feigned PTSD}

Of critical concern is the range of the nature and severity of symptoms that real sufferers of PTSD - a clearly very heterogeneous population - may exhibit, and therein the challenge as to how one might distinguish real from malingered illness. There is a considerably greater incidence of PTSD following an interpersonal trauma (such as a serious sexual assault) than a non-interpersonal one (such as a car accident), but once again there is a wide degree of variability, individual predisposition is an important factor, and it is not currently possible to give an individualised likelihood of a given individual developing PTSD after a putative trauma.

As Hall \& Hall (2006) note, fundamentally PTSD is 'easily malingered', and it has been referred to as the 'diagnosis of choice' in civil litigation. In simulations, individuals have been shown to be able to portray PTSD relatively easily when provided with self-rating scales 
(Burges 2001), although in the wider literature estimates of the actual rates of false presentation vary widely, from 1 to $50 \%$, depending on the referral source and study type. Hall $\&$ Hall have proposed a list of clinically differentiating symptoms between 'real' and malingered PTSD (Table 1), but with regard to their description we refer the reader to our discussion below of clinical assessment ('The assessment: breaking bad or faking bad?') and our forthcoming article (Rix 2017) on medicolegal reporting.

\section{Adult attention-deficit hyperactivity disorder}

Most work on malingering of attention-deficit hyperactivity disorder (ADHD) has focused on university/college populations. This is a group with potentially sizeable benefits from a feigned diagnosis: from extra tuition and support, through additional time during examinations, to differential instructions to examiners about marking criteria. Furthermore, the pharmacological treatment of ADHD, stimulant medication, has been shown to enhance cognitive performance in healthy individuals (Bagot 2014), part of a broader phenomenon known as nootropic drug use; there are data on individuals surreptitiously obtaining such prescriptions for themselves for financial gain through illicit resale. Work by Pella et al (2012) estimated malingering in just over $10 \%$ of individuals completing psychometric testing when external, but non-litigating, incentives were noted to be present, although the range in the wider literature is significant, with rates of up to almost $50 \%$ in some instances.

Musso \& Gouvier (2014) systematically evaluated the literature on the malingering of ADHD in college students. In the 19 reported studies, self-report questionnaires were found to be insensitive to malingering, and the profiles of malingerers and non-malingerers were too similar to confidently detect the feigned condition. Diagnosis in adult ADHD typically utilises clinical scales such as the Wender Utah Rating Scale, but as with PTSD, it is not difficult for the malingering individual to anticipate how to manipulate answers, and, put simply, no questionnaire - even the Conners' Adult ADHD Rating Scales (CAARS) and the Clinical Assessment of Attention Deficit - Adult (CAT-A), which have in-built validity matrices - was adequately robust in determining false positives. A difficulty in detection arises from the fact that ADHD simulators typically admit to using multiple strategies to feign illness, which might prove impossible for a single tool or screen to take into account. These include feigning general inattention, ignoring some stimuli types, intentional errors of commission and omission
TABLE 1 Suggested differential indicators of true and malingered post-traumatic stress disorder (PTSD)

\begin{tabular}{|c|c|}
\hline 'True' PTSD & 'Malingered' PTSD \\
\hline Initially more reserved discussing symptoms & Calls early and frequent attention to symptoms \\
\hline $\begin{array}{l}\text { Flashbacks involve more than one } \\
\text { sensation, feel as if they are occurring } \\
\text { contemporaneously, result in trauma- } \\
\text { appropriate actions }\end{array}$ & $\begin{array}{l}\text { Flashbacks primarily visual and similar to what } \\
\text { is seen in a movie, involve only one sensation, } \\
\text { result in premeditated actions }\end{array}$ \\
\hline Dissociative states when traumas are recalled & $\begin{array}{l}\text { Claims dissociative amnesia, with none of } \\
\text { their actions remembered }\end{array}$ \\
\hline $\begin{array}{l}\text { Frequent nightmares: themes are similar, but } \\
\text { frequency and content vary }\end{array}$ & $\begin{array}{l}\text { Nightmares are frequent, identical and occur } \\
\text { with each sleep }\end{array}$ \\
\hline $\begin{array}{l}\text { Partner reports a light sleeper with lots of } \\
\text { movement }\end{array}$ & No collateral report of sleep difficulties \\
\hline $\begin{array}{l}\text { Apportions at least some self-blame for } \\
\text { problems }\end{array}$ & Overtly and frequently blames others \\
\hline Minimises symptom severity & $\begin{array}{l}\text { Exaggerates symptom severity, often in a } \\
\text { 'textbook' or rehearsed manner }\end{array}$ \\
\hline Difficulties relaxing and working & $\begin{array}{l}\text { Enjoys recreational activities; justifies as } \\
\text { therapeutic }\end{array}$ \\
\hline Minimises involvement in trauma & $\begin{array}{l}\text { Exaggerates role in trauma, to the point of } \\
\text { being heroic }\end{array}$ \\
\hline $\begin{array}{l}\text { May use prior problems to explain current } \\
\text { deficits }\end{array}$ & Reports no problems prior to the trauma \\
\hline Seeks treatment on the guidance of others & Seeks treatment in the context of litigation \\
\hline Psychotic symptoms & Denies psychotic symptoms \\
\hline $\begin{array}{l}\text { A more fluctuating course, with some } \\
\text { improvement over time }\end{array}$ & Chronic non-fluctuation \\
\hline Relatively stable pre-event work history & $\begin{array}{l}\text { History of multiple lawsuits, unstable work } \\
\text { history }\end{array}$ \\
\hline Some survivor guilt & No survivor guilt \\
\hline
\end{tabular}

Source: modified from Hall \& Hall (2006), with permission of Elsevier

(including some choosing to do so only on 'harder' test items, thus potentially effectively mimicking a 'real' as opposed to random response pattern), skipping items, and intentionally responding either unduly quickly or slowly and without care (Quinn 2003; Harrison 2007).

Musso \& Gouvier concluded that ADHD malingerers were able to produce plausible profiles on most tools utilised to diagnose ADHD and that there remained a substantial need to develop condition-specific malingering tests.

\section{Somatoform and dissociative disorders}

'Nothing, it may be said, resembles malingering more than hysteria; nothing hysteria more than malingering. In both alike we are confronted with the same discrepancy-between fact and statement, between objective sign and subjective symptom.' A. Bassett Jones \& L. J. Llewellyn, Malingering, or, The Simulation of Disease, 1918.

Somatisation disorder (relabelled somatic symptom disorder in DSM-5) and dissociative disorders, with their focus on physical symptomatology, can be very challenging for mental health specialists, not least as they are diagnoses of exclusion - often 


\section{BOX 1 Phenomenologically 'typical' and 'atypical' aspects of auditory verbal hallucinations (AVH)}

\section{'Typical' AVH}

- Described as being like hearing someone else speak; the accent differs from the individual's own voice

- Acoustically clear - 'mumbling' voices common, but rare to find alone

- Experienced as very real

- Typically critical or abusive

- May be commands, but some resistance to these

'Atypical' AVH (generally $<5 \%$ of cases)

- Changes gender mid-sentence; sounds like a robot or animals; hear only female or children's voices

- All voices mumbling or vague; normal speaking tone is shouting or yelling

- Cannot recall when they first occurred

- No positive comments or voices; unbearably distressing; never critical and never comments on behaviour

- Often repetitive in what they say

- Some control over the voices

- Commonly last for hours, but can speak for minutes or seconds

- More than one voice (although one is often 'dominant' and a single voice is not uncommon)

- Occur several times, or most of the time, each day

- Can talk interactively with the voice(s)

- Obeys all commands and they cannot be resisted

- Never hears the same voices or themes

- No control over the voices and no coping strategies; voices unaffected by affective state or environment (e.g. being alone)

- Continuous (although up to half with 'typical' AVH will say they are always 'present', even if not speaking)

- Voice location: whether 'inside' or 'outside' of the head, but atypical to originate from other parts of the body (utility in determining whether voices are true or malingered is less well established)

(Abridged and modified from McCarthy-Jones \& Resnick 2014)

necessitating many investigations and reviews over considerable periods of time - and there can be considerable resistance to the suggestion that problems are 'in the head', particularly in the case of somatisation. It can be a fraught area, where there can be intense debate around concepts and even word definitions such as 'somatoform', 'functional', 'overlay', 'medically unexplained' and (somewhat historically, but still problematically as the term remains in multiple parts of ICD-10) 'hysteria'.

Unfortunately, there is no well-evidenced work on symptom variation, and the sole clear differentiator of the malingerer is in intent: in true illness, symptom production is unconscious; in malingering it is not. As it is impossible for a healthcare professional to know the motive of a nondisclosing individual, and given the substantial task of diagnosing even true cases of somatoform and dissociative disorders, the clinician should express their opinion with caution.

\section{Psychosis}

'If sanity and insanity exist, how shall we know them?' - D. L. Rosenhan, On being sane in insane places, Science, 1973.
Rosenhan's landmark paper in Science (1973) on healthy volunteers who achieved psychiatric admission through feigned voice-hearing has cast a long shadow over psychiatry and clinicians' perceptions of their abilities to determine real psychotic symptoms. Not only did professionals fail to recognise the deception in this classic experiment - a failure all the more alarming given the unusual phenomenology - but thereafter, in the second arm of the study, when Rosenhan (falsely) informed staff that 'fake patients' would be admitted, they determined that there was a high likelihood that individuals were feigning mental illness in just over a fifth of the 193 assessments.

Auditory verbal hallucinations (AVH) have been argued to be the psychotic symptom most commonly malingered by criminal defendants, which McCarthy-Jones \& Resnick (2014) note may be due to a public association with insanity and thus the use of AVH as part of a legal defence. In a review of the literature, they tabulate phenomenological properties of hallucinations that may be used to assist the determination of their veracity: Box 1 highlights their main findings.

With regard to delusions, following a literature review of the topic, Mason et al (2014) propose the 'IDEA' acronym for what they label 'probable symptoms of malingering delusions':

- Inconsistent behaviour relative to descriptions of the delusion

- Dramatic or bizarre content without disorganised presentation

- Eagerness to talk about the delusion and being specific in the details

- Abrupt onset or termination of the delusion.

McCarthy-Jones \& Resnick's delineation of factors into 'typical' and 'atypical', rather than 'true' and 'malingered' (Box 1), is especially helpful. As with the proposed list of symptom differentiators for $\mathrm{ADHD}$, we refer the reader to the next section for the assessment of symptoms, and to our forthcoming article (Rix 2017) for the medicolegal challenges that might be faced.

\section{The assessment: breaking bad or faking bad?}

'Neurosis has an absolute genius for malingering. There is no illness which it cannot counterfeit perfectly. If it is capable of deceiving the doctor, how should it fail to deceive the patient?' Marcel Proust, In Search of Lost Time, vol. 2: The Guermantes Way, 1920/1921.

\section{The clinical history}

A non-judgemental interviewing style is clearly always important, but even more so if there may be malingering. It is essential to remain open-minded 
and dispassionate - this is as helpful for optimising the clinician's assessment as it is for encouraging the individual's full engagement. Furthermore, there is evidence that such an approach actually facilitates more egregious lying where this occurs (Resnick 1995), and that perceived clinician scepticism or hostility may lead the individual to become unduly defensive and less communicative (Knoll 2006). If the issue of malingering is directly raised, it should be done so in a sympathetic manner, for example 'one can imagine that faced with such difficulties, it might have been tempting/ seemed reasonable to...' and so forth.

Wiley (1998) argued that an open-ended question style, particularly at the interview's beginning, encourages malingerers to talk more broadly and, if uninterrupted, provide detail that is conflicting or contradictory. It is noteworthy that malingerers can have less awareness of secondary loss in their purported illness, for example a loss of social role or function, with greater emphasis on the gain, such as compensation, avoiding a punishment and so on. An attuned clinician may pick up a lack of awareness of, or interest in, losses. Furthermore, some individuals will express disinterest, reject or have a history of rejecting inputs that might assist, for example medication or therapy, or an occupational role or activity that accommodates any loss or 'disability'. So the assessment should begin by asking the individual to describe the symptoms they are experiencing, when these started, whether they had suffered them previously, whether they vary and what if anything makes them better or worse. Allcott et al's survey (2014) of medical experts found that disparity between the presenting complaint and the history elicited was the most relied on factor in considering putative malingering, and interestingly, significantly fewer endorsed a discrepancy in behaviour as being so indicative.

Collateral data can be useful, although one must be mindful that this can be directly or indirectly manipulated: a friend or relative might have an investment in any secondary gain or might be innocently influenced by the malingerer. Similarly, it is possible that only supporting documentation might be presented, and any conflicting or undermining documentation withheld. Where possible, any interviews with informants should be conducted separately, mindful that even in true illness no two accounts will ever be identical; it should be documented how the collateral assessment was conducted and, where appropriate, if there was any relevant discussion between the collateral informant and the examinee.

In all interviews, a most crucial aspect is to regularly assess one's style and approach for the presence of confirmatory biases, namely the intentional or unintentional seeking of information to confirm or refute a hypothesis or preconception, to the exclusion of other material. True and malingered presentations can vary for many reasons, including:

- the natural range of presentations inherent in all mental illnesses, including geographical, social and cultural variation

- personality and temperamental factors altering how a given individual presents, builds a rapport and engages with assessing professionals, including geographical, social and cultural variation.

It is critical to remember that there can be manipulation (insofar as external gain is the primary motivator) and symptom exaggeration in someone with true illness. No symptom or lack of a symptom is pathognomonic of either malingering or veridical illness in any instance, and one must be wary of what Faust (1995) called 'educated guesses or clinical lore, which have not been properly validated and screened'.

Now that detailed information about mental disorders is so readily available on the internet as well as in popular books written for the lay public, it is worthwhile asking examinees if they have read anything about their condition or its symptomatology and, if they have, establishing the source. For similar reasons, enquiry should be made as to whether they know anyone else with a similar condition or symptoms.

\section{Psychometric testing}

There has been an understandable drive to develop validated sensitive and specific markers of clinical malingering, particularly as this endeavour has been reasonably successful in cognitive and memory examination (Tracy 2014). Four major types of test exist: general symptom or personality factor tests such as the Minnesota Multiphasic Personality Inventory (MMPI); malingeringspecific clinical scales such as the Structured Inventory of Malingered Symptomatology (SIMS); symptom validity tests (SVTs), which are primarily used in cognitive assessment, such as the Test of Memory Malingering (TOMM); and (currently least successfully) biomarkers, including physiological (e.g. heart rate and blood pressure) and neuroendocrine (e.g. cortisol) measures, and neuroimaging (Choi 2015). The use of general personality scales is predicated on evaluation of overall response patterns and comparison with normative (healthy control and true illness) data, with some including embedded validity (bias 
response) components. Most specific malingering scales can be used across different conditions, and typically ask about rare symptoms, paired symptoms that seldom occur together, fantastical or preposterous symptoms, and symptoms untrained individuals might mistakenly regard as part of mental illness and/or incorrectly regard as not indicative of mental illness. Symptom type and reporting rates are usually recorded, sometimes with self-rating on symptom severity.

Table 2 gives an overview of the use of psychometric tests for various conditions. These have been used and validated for a range of conditions and populations, including forensic settings (Steffan 2010). The main point to note is their limitations (Kleinman 2015): they can support or undermine evidence of a true condition, but most have low-tomoderate sensitivity (Rubenzer 2009). Therefore they should never be relied on of themselves, and their results should be reported with appropriate caution as one part of a full assessment; our second article (Rix 2017) will discuss this more fully.

\section{Caveats in using psychometric tests: the example of PTSD}

Highlighting the difficulty in using psychometric tests, in a study of war veterans with previously diagnosed PTSD, Freeman et al (2008) found that the majority (53\%) scored 'clear symptom exaggeration' (and a further 24\% scored 'indeterminate') as measured by the Structured Interview of Reported Symptoms (SIRS) scale. There was no evidence that any of the participants did not have true PTSD, and the authors note that war veterans with PTSD may be "prone to certain response "styles" inherent to the complex cognitive and emotional illness of PTSD'. Furthermore, Lees-Haley described (1997) a common MMPI-2 profile in personal injury litigants that 'suggest[s] poor insight and denial, which may support the thesis that plaintiff exaggeration is better thought of in terms of pathology or rationalization than malingering, which implies conscious intent [...] The modal plaintiff appears to be an unhappy somatizer involved in a social context that encourages rationalization, projection of blame, and complaining'.

Another challenge is that the majority of psychometric test studies have been carried out on particular subpopulations (such as war veterans or specific - typically Western - cultural groups), and have not necessarily been suitably validated on other groups. Box 2 provides a vignette, based on a composite of clinical experiences, in which an individual 'failed' testing, but might have had true mental illness.

\section{Symptom validity tests}

SVTs have a less clear role in assessing putative cases of the aforementioned conditions than they do in cases of posited neurocognitive and memory dysfunction, and their use needs thought and care. There are data on SVT performance in malingered PTSD - for reviews, see Rubenzer (2009) and Demakis \& Elhai (2011) - and it is of course noteworthy that memory and concentration difficulties are not uncommon (although not inevitable) in this illness. SVTs can also be used in $\mathrm{ADHD}$ - they are currently the best supported scales in this cohort but with some significant caveats (Williamson 2014) - predicated on ADHD malingerers (falsely) anticipating that their 'poor attention' might translate to these cognitive tests.

Merten \& Merckelbach (2013) undertook a critical review of SVT use in determining malingering in somatoform and dissociative disorders. The background challenge is that it has been argued that the (poorly understood) psychological processes underlying somatoform and dissociative disorders could produce a response bias that would erroneously lead to (a false positive) SVT failure, and thus the uncertainty of how to interpret any findings. They note the lack of empirical support for such a position, and put forward the argument (which also lacks good empirical support) that SVT failure does indeed represent malingering in these conditions.

In psychoses, individuals commonly have a wide range of cognitive deficits that manifests with an average deficit of one standard deviation below the healthy population in routine psychometric evaluation (Rowe 2015), and SVTs have been shown to be valid in benchmarking malingering of neurocognitive functioning - not psychotic symptoms - despite the presence of positive and negative symptoms (Schroeder 2011).

Nevertheless, serious challenges remain in all instances of SVT use, not least because nonneurocognitive disorders are diagnosed by clinical histories. One would not diagnose true ADHD, for example, solely on the basis of cognitive test performance (indeed, this is not even part of most clinical ADHD assessments despite inattention being a cardinal feature), and thus it is not reasonable to use such testing to either rule out true illness (for example in someone with genuine but sub-diagnostic-threshold poor attention), or necessarily infer malingering. Further, there is the challenge of both false negatives and false positives in SVT use: malingering individuals might choose to engage with and perform well on (thus 'passing') SVT testing; conversely, individuals - including those with a true illness - can sabotage and not 


\begin{tabular}{|c|c|c|c|c|}
\hline Condition & $\begin{array}{l}\text { Specific malingering scales/ } \\
\text { measurements }\end{array}$ & Notes & $\begin{array}{l}\text { General scales/ } \\
\text { measurements }\end{array}$ & Notes \\
\hline \multirow[t]{5}{*}{$\begin{array}{l}\text { Post-traumatic } \\
\text { stress disorder } \\
\text { (PTSD) }\end{array}$} & $\begin{array}{l}\text { Morel Emotional Numbing Test } \\
\text { for PTSD (MENT) }\end{array}$ & $\begin{array}{l}\text { Specifically designed for PTSD, a } \\
\text { 'forced-choice' test. Tests facial } \\
\text { affect recognition. Data support } \\
\text { use, though study variations }\end{array}$ & $\begin{array}{l}\text { Minnesota Multiphasic } \\
\text { Personality Inventory, second } \\
\text { edition (MMPI-2) }\end{array}$ & $\begin{array}{l}\text { Includes Infrequency, Fake Bad, } \\
\text { Response Bias subcomponents. } \\
\text { Mixed evidence base on ability to } \\
\text { detect malingering }\end{array}$ \\
\hline & $\begin{array}{l}\text { Miller Forensic Assessment of } \\
\text { Symptoms Test (M-FAST) }\end{array}$ & $\begin{array}{l}\text { Derived from the SIRS; quicker, } \\
\text { simpler to use. Evidence to } \\
\text { support its use in PTSD, but } \\
\text { perhaps better as a quick } \\
\text { screening tool }\end{array}$ & $\begin{array}{l}\text { Millon Multiaxial Clinical } \\
\text { Inventory III (MMCl-III) }\end{array}$ & $\begin{array}{l}\text { Validity in detecting PTSD } \\
\text { malingering challengeable }\end{array}$ \\
\hline & $\begin{array}{l}\text { Personality Assessment Index } \\
\text { (PAI) }\end{array}$ & $\begin{array}{l}\text { Has three subscales: MI, } \\
\text { NIM and RDF. Considered a } \\
\text { reasonable screen rather than } \\
\text { diagnostic tool }\end{array}$ & $\begin{array}{l}\text { Physiological measures of } \\
\text { arousal; responses to script- } \\
\text { driven imagery and/or sudden } \\
\text { loud sounds }\end{array}$ & \multirow[t]{3}{*}{$\begin{array}{l}\text { At present, physiological } \\
\text { measures are not sufficiently } \\
\text { sensitive or specific to utilise } \\
\text { clinically; primarily of use in } \\
\text { research }\end{array}$} \\
\hline & $\begin{array}{l}\text { Structured Inventory of } \\
\text { Malingered Symptomatology } \\
\text { (SIMS) }\end{array}$ & Data to support use & $\begin{array}{l}\text { Cortisol and other } \\
\text { neuroendocrine markers }\end{array}$ & \\
\hline & $\begin{array}{l}\text { Structured Interview of } \\
\text { Reported Symptoms (SIRS) }\end{array}$ & $\begin{array}{l}\text { Some consider this the gold } \\
\text { standard. Evidence to support } \\
\text { use in PTSD, but much evidence } \\
\text { from non-PTSD populations }\end{array}$ & Neuroimaging & \\
\hline \multirow[t]{3}{*}{$\begin{array}{l}\text { Attention- } \\
\text { deficit } \\
\text { hyperactivity } \\
\text { disorder } \\
\text { (ADHD) }\end{array}$} & \multirow[t]{3}{*}{$\begin{array}{l}\text { Symptom validity tests (SVTs) } \\
\text { such as the Word Memory Test } \\
\text { (WMT) and Test of Memory } \\
\text { Malingering (TOMM) }\end{array}$} & \multirow{3}{*}{$\begin{array}{l}\text { The standard for detecting } \\
\text { malingering in memory and } \\
\text { cognition evaluation. Less } \\
\text { studied in ADHD; overall } \\
\text { data are better than other } \\
\text { test batteries or scales, but } \\
\text { inadequate sensitivity in most } \\
\text { instances }\end{array}$} & $\begin{array}{l}\text { General ADHD diagnostic } \\
\text { self-questionnaires: ADHD } \\
\text { Behavior Checklist- } \\
\text { Retrospective; College ADHD } \\
\text { Response Evaluation; Conners' } \\
\text { Adult ADHD Rating Scales }\end{array}$ & $\begin{array}{l}\text { Data indicate these are very poor } \\
\text { at delineating malingered from } \\
\text { feigned illness }\end{array}$ \\
\hline & & & MMPI-2 & $\begin{array}{l}\text { Malingerers have been shown } \\
\text { to score more highly on multiple } \\
\text { validity subscales, including } \\
\text { Infrequency, Response Bias, Fake } \\
\text { Bad, Henry-Heilbronner Index. } \\
\text { However, the sensitivity and } \\
\text { specificity can be challenged }\end{array}$ \\
\hline & & & $\begin{array}{l}\text { Neuropsychological test } \\
\text { batteries: Test of Variables of } \\
\text { Attention; Integrated Visual and } \\
\text { Auditory Continuous } \\
\text { Performance Test; Woodcock- } \\
\text { Johnson Psycho-Educational } \\
\text { Battery; Trail Making Test; } \\
\text { Stroop test }\end{array}$ & $\begin{array}{l}\text { In general, evidence suggests } \\
\text { that malingering individuals are } \\
\text { able to produce profiles similar to } \\
\text { those with ADHD }\end{array}$ \\
\hline $\begin{array}{l}\text { Somatoform } \\
\text { and } \\
\text { dissociative } \\
\text { disorders }\end{array}$ & SVTS & $\begin{array}{l}\text { Merten \& Merckelbach (2013) } \\
\text { argue that negative response } \\
\text { bias (SVT failure) delineates } \\
\text { malingerers. This does not have } \\
\text { strong empirical backing, and } \\
\text { any such statement will need } \\
\text { considerable care }\end{array}$ & Physiological responses & $\begin{array}{l}\text { Data do not support differences } \\
\text { between malingerers and non- } \\
\text { malingerers }\end{array}$ \\
\hline \multirow[t]{2}{*}{$\begin{array}{l}\text { Schizophrenia/ } \\
\text { psychoses }\end{array}$} & SVTs & $\begin{array}{l}\text { Data indicate that they are valid } \\
\text { in detecting malingering of } \\
\text { cognitive symptoms }\end{array}$ & MMPI & $\begin{array}{l}\text { Data to support, but } \\
\text { interpretation needs caution }\end{array}$ \\
\hline & SIRS, SIMS & Data to support & & \\
\hline
\end{tabular}

MI, Malingering Index; NIM, Negative Impression Management scale; RDF, Rogers Discriminant Function.

engage with testing for many reasons outwith malingering. The previously noted ADHD data are sobering in this regard, with illness simulators adopting a range of strategies, including choosing not to feign on easier tests. A legal case might be furthered by challenging an individual's credibility following a poor SVT performance, but a clinician must be quite circumspect in projecting this to posit that a clinical history and relevant symptomatology, untested by a SVT, had been malingered. A PTSD-specific SVT, the Morel Emotional Numbing Test for PTSD (MENT), does exist, although it is based on facial affect recognition, and thus 'failure' might, as on all 


\section{BOX 2 A case of possible exaggeration in true PTSDa}

Mr A was a 33-year-old Trinidadian national detained under immigration powers. He was from an impoverished background, and had left school aged 11 with no qualifications and extremely limited literacy skills. He had never worked, and he smoked cannabis regularly through his adult life; he had served short prison sentences in both Trinidad and the UK for theft. His social network and life in the UK prior to immigration detention had been very limited, mainly consisting of spending time with other Trinidadians; he had no prior experience of mental health services. From his account he had been kidnapped and assaulted by a local gang in Trinidad, as part of retribution against alleged criminal activity by his brother, leading him to flee that country. He described psychological sequelae secondary to this, and said that his life would be in danger if he returned to Trinidad; the UK Border Agency challenged the veracity of his account and his psychiatric history.

On psychiatric assessment, he gave a history consistent with post-traumatic stress disorder (PTSD) secondary to several days' life-threatening torture, and his score on the PTSD CheckList (Civilian Version) was also consistent with this diagnosis. Two malingering tests were applied. He scored 56 on the Structured Inventory of Malingered Symptomatology (SIMS): scores of above 14 have been shown to have 95.6\% sensitivity and $87.9 \%$ specificity for malingering. He also completed the Test of Memory Malingering (TOMM) (in addition to other cognitive batteries) as he complained of memory problems following his assault. Standard cognitive testing showed wideranging and significant deficits, but his score on the TOMM was 30/50: even individuals with dementia have been shown to score over $45 / 50$, and scores less than this are considered consistent with malingering. Of note, owing to his limited literacy skills, against usual practice all psychometric tests had to be filled in by the assessing psychiatrist after reading the questions and possible answers to him.

There were two main potential interpretations of Mr A's history, presentation and test data. First, it was possible that a combination of cultural, educational and personality factors and a (conscious or otherwise) desire to impress on professionals the significance of his mental state - had affected his engagement with assessment and testing, and that these - and the failed malingering tests - masked a true mental illness (PTSD). A second hypothesis was that his performance on the malingering tests constituted broader misrepresentation of his case history and symptoms. It was not possible, through psychiatric examination, to determine the veracity of his claims of kidnapping and assault, or of the risks posed to his life should he return to Trinidad. The discrepancies across his history and examination during the assessment were such that the assessing psychiatrist could not with confidence attribute his clinical presentation to an orthodox mental illness. A full account of the history, examination, test data and interpretations of these was put to the court to determine Mr A's credibility as a witness. His testimony was considered unreliable by the Home Office, and his asylum claim ultimately dismissed.

a. This is a composite of several cases - no individual's complete details are used

SVTs, show a lack of effort and engagement, rather than 'prove' PTSD malingering.

\section{Conclusions}

Delineating 'true' from 'feigned' psychiatric symptomatology remains a challenge for clinicians, although the literature demonstrates that there are differences between various 'conditions'. Psychometric testing can have an important supportive role, but one needs to understand

MCQ answers

1 b $\quad 2$ d $\quad 3$ a $\quad 4 c \quad 5$ e the scientific evidence underpinning the various tests across the range of potential assessment uses. A critical issue is the manner in which one undertakes the whole assessment process when malingering is suspected. Our second article (Rix 2017), illustrated by some recently reported legal cases, will describe the medicolegal challenges faced and, critically, propose a template for the logical, balanced presentation of clinical findings, explaining how it may be used to assist in the delivery of justice.

\section{Acknowledgement}

D.K.T wishes to thank Dr Mark Tarn and Dr Amlan Basu for their long-term collaboration and professional and intellectual discussions on the nature of malingering that have helped shape this work.

\section{References}

Allcott D, Anderson S, Friedland D, et al (2014) How do experts reporting for the legal process validate symptoms? The results of a survey. Medicine, Science, and the Law, 54: 68-73.

American Psychiatric Association (2013) Diagnostic and Statistical Manual of Mental Disorders (5th edn) (DSM-5). APA.

Bagot KS, Kaminer Y (2014) Efficacy of stimulants for cognitive enhancement in non-attention deficit hyperactivity disorder youth: a systematic review. Addiction, 109: 547-57.

Burges C, McMillan TM (2001) The ability of naive participants to report symptoms of post-traumatic stress disorder. British Journal of Clinical Psychology, 40: 209-14.

Choi 0 (2015) Using fMRI for lie detection: ready for court? In Psychiatric Expert Testimony: Psychiatric Expert Testimony (eds KJ Weiss, C Watson): 84-101. Oxford University Press.

Demakis GJ, Elhai JD (2011) Neuropsychological and psychological aspects of malingered posttraumatic stress disorder. Psychological Injury and Law, 4: 24-31.

Erichsen JE (1882) On Concussion of the Spine: Nervous Shock and Other Obscure Injuries of the Nervous System in their Clinical and Medico-Legal Aspects. Bermingham \& Co.

Faust D (1995) The detection of deception. Neurologic Clinics, 13: 255-65.

Freeman T, Powell M, Kimbrell T (2008) Measuring symptom exaggeration in veterans with chronic posttraumatic stress disorder. Psychiatric Research, 158: 374-80.

Hall RCW, Hall RCW (2006) Malingering of PTSD: forensic and diagnostic considerations, characteristics of malingerers and clinical presentations. General Hospital Psychiatry, 28: 525-35.

Harrison AG, Edwards MJ, Parker KC (2007) Identifying students faking ADHD: Preliminary findings and strategies for detection. Archives of Clinical Neuropsychology, 22: 577-88.

Hunt EJ, Wessely S, Jones N, et al (2014) The mental health of the UK Armed Forces: where facts meet fiction. European Journal of Psychotraumatology, 5: 23617 (http://dx.doi.org/10.3402/ejpt.v5.23617).

Jones, E, Milroy, H (2016) Stolen trauma: why some veterans elaborate their psychological experience of military service. Defense \& Security Analysis, 32: 51-63.

Kanaan RA, Wessely SC (2010) The origins of factitious disorder. History of the Human Sciences, 23: 68-85.

Kleinman SB, Stewart L (2004) Psychiatric-legal considerations in providing mental health assistance to disaster survivors. Psychiatric Clinics of North America, 27: 559-70.

Kleinman SB, Martell D (2015) Failings of trauma-specific and related psychological tests in detecting post-traumatic stress disorder in forensic settings. Journal of Forensic Sciences, 60: 76-83. 
Knoll J, Resnick PJ (2006) The detection of malingered post-traumatic stress disorder. Psychiatric Clinics of North America, 29: 629-47.

Lees-Haley PR (1997) MMPI-2 base rates for 492 personal injury plaintiffs: implications and challenges for forensic assessment. Journal of Clinical Psychology, 53: 745-55.

Lipman FD (1962) Malingering in personal injury cases. Temple Law Quarterly, 35: 141-62

Lund FB (1941) Galen on Malingering, Centaurs, Diabetes and Other Subjects More or Less Related. Columbia University Press.

Mason AM, Cardell R, Armstrong M (2014) Malingering psychosis: guidelines for assessment and management. Perspectives in Psychiatric Care, 50: 51-7

McCarthy-Jones S, Resnick PJ (2014) Listening to voices: the use of phenomenology to differentiate malingered from genuine auditory verbal hallucinations. International Journal of Law and Psychiatry, 37: 183-9.

Merten T, Merckelbach H (2013) Symptom validity testing in somatoform and dissociative disorders: a critical review. Psychological Injury and Law, 6: $122-37$

Mittenberg W, Patton C, Canyock EM, et al (2002) Base rates of malingering and symptom exaggeration. International Journal of Law and Psychiatry, 24: 1094-102.

Musso MW, Gouvier WD (2014) "Why is this so hard?" A review of detection of malingered ADHD in college students. Journal of Attention Disorders, 18: 186-201.

Pella RD, Hill BD, Shelton JT, et al (2012) Evaluation of embedded malingering indices in a non-litigating clinical sample using control, clinical, and derived groups. Archives of Clinical Neuropsychology, 27: 45-57.

Quinn CA (2003) Detection of malingering in assessment of adult ADHD. Archives of Clinical Neuropsychology, 18: 379-95.

Resnick P (1995) Guidelines for the evaluation of malingering in posttraumatic stress disorder. In Posttraumatic Stress Disorder in Litigation: Guidelines for Forensic Assessment (ed R Simon): 117-34. American Psychiatric Press.

Richards L (2010) The Black Art: British Clandestine Psychological Warfare against the Third Reich. Psywar.
Rix KJB, Tracy DK (2017) Malingering mental disorders: medicolegal reporting. BJPsych Advances, in press.

Rosenhan DL (1973) On being sane in insane places. Science, 179: 250-8.

Rowe AR, Merce, L, Casetti V, et al (2015) Dementia praecox redux: a systematic review of the nicotinic receptor as a target for cognitive symptoms of schizophrenia. Journal of Psychopharmacology, 29: 197-211.

Rubenzer S (2009) Posttraumatic stress disorder: assessing response style and malingering. Psychological Injury and Law, 2: 114-42.

Schroeder RW, Marshall PS (2011) Evaluation of the appropriateness of multiple symptom validity indices in psychotic and non-psychotic psychiatric populations. Clinical Neuropsychologist, 25: 437-53.

Slobodin 0, de Jong JT (2015) Mental health interventions for traumatized asylum seekers and refugees: What do we know about their efficacy? International Journal of Social Psychiatry, 61: 17-26.

Steffan JS, Morgan RD, Lee J, et al (2010) A comparative analysis of MMPI-2 malingering detection models among inmates. Assessment, 17: 185-96.

Townsend M (2016) Many military veterans' PTSD claims 'fabricated or exaggerated'. The Guardian, 23 January (http://www.theguardian.com/ uk-news/2016/jan/23/many-military-veterans-ptsd-claims-fabricated-orexaggerated). Accessed 14 October 2016

Tracy DK (2014) Evaluating malingering in cognitive and memory examinations: a guide for clinicians. Advances in Psychiatric Treatment, 20: 405-12.

Wiley SD (1998) Deception and detection in psychiatric diagnosis Psychiatric Clinics of North America, 21: 869-93.

Williamson KD, Combs HL, Berry DT, et al (2014) Discriminating among ADHD alone, ADHD with a comorbid psychological disorder, and feigned ADHD in a college sample. Clinical Neuropsychologist, 28: 1182-96.

World Health Organization (1992) The ICD-10 Classification of Mental and Behavioural Disorders: Clinical Descriptions and Diagnostic Guidelines. $\mathrm{WHO}$

Yehuda R, Vermetten E, McFarlane AC, et al (2014) PTSD in the military: special considerations for understanding prevalence, pathophysiology and treatment following deployment. European Journal of Psychotraumatology, 5: doi 10.3402/ejpt.v5.25322.
MCQs

Select the single best option for each question stem

1 'Symptoms' considered more consistent with malingered PTSD include:

a frequent nightmares with a common theme but varying content

b frequent nightmares with a common theme and repeated content

c relatively stable pre-event work history

d flashbacks that involve more than one sense and feel as if they are occurring at that moment

e dissociative states when traumas are recalled.

2 When assessing a case of suspected malingering:

a one should not raise the possibility of malingering with an interviewee

b an interviewee's statements on the primacy of external motivators/gain can generally be considered diagnostic c differences from a collateral informant's statement typically infer a dishonest account

d no symptom or absence of a symptom can ever be considered pathognomonic of malingering

e there are predictable clinical differences between culturally varying cohorts.

\section{Symptoms considered more consistent} with 'typical' or non-malingered hallucinations include:

a voices that are acoustically clear

b voices that are all mumbling or vague c inability to recall when voices first occurred

d voices that never repeat what they say

e voices that are continuous.

4 Symptom validity tests (SVTs):

a should not be used for non-cognitive disorders

$\mathrm{b}$ are best evidenced for PTSD

c demonstrate 'effort' not 'motivation' $\mathrm{d}$ are designed to be resistant to attempts to sabotage

e can be reliably used to infer malingering in the clinical history.

5 Challenges in PTSD assessments do not include:

a so-called 'warrior embellishment', meaning that veterans may subconsciously exaggerate their histories

b considerable differences in the scientific literature between military and non-military cohorts

c significant real trauma suffered by many PTSD malingerers

$d$ the potential influence on the assessment of clinicians' positive and negative countertransference biases

e a lack of robust evidence to support psychometric testing in suspected malingering. 